\title{
Availability of caregiver-friendly workplace policies: an international scoping review follow-up study
}

Caregiverfriendly workplace policies

Frances Lorenz

School of Interdisciplinary Sciences, McMaster University, Hamilton, Canada Lisa Whittaker

School of Earth, Environment and Society, McMaster University, Hamilton, Canada Julia Tazzeo

Arts and Science, McMaster University, Hamilton, Canada, and Allison Williams

School of Earth, Environment and Society, McMaster University, Hamilton, Canada

\begin{abstract}
Purpose - The purpose of this scoping review was to identify the availability of caregiver-friendly workplace policies (CFWPs) from January 2015 to June 2019.

Design/methodology/approach - In order to determine changes over time, the present review is consistent with the methodology used in a scoping review of CFWPs conducted by the same research group five years earlier. This included applying an iterative database search to identify relevant articles, applying inclusionexclusion criteria and performing qualitative thematic analysis on eligible articles. Both academic literature and literature that is not peer-reviewed were considered.

Findings - A total of 80 papers were included, with 82 unique workplaces identified. Three main qualitative themes were discussed: (1) inclusivity, (2) generosity and (3) culture. The finance, education, healthcare and technology industries were most generous. The most common CFWPs offered were support services; paid leave; backup adult care and flexible work arrangements.

Practical implications - This review narrows the gap in the literature by providing a comprehensive synthesis of CFWPs availability to better understand how workplaces are currently supporting caregiveremployees (CEs) while providing recommendations on how to support CEs moving forward.

Originality/value - This paper discusses significant differences from the first scoping review undertaken by the same research group five years ago, suggesting that progress has been made in the workplace culture needed to accommodate carer-employees.
\end{abstract}

Keywords Caregiver-employees, Caregiver-friendly workplace policies, Workplaces, Scoping review, Employers, Eldercare, Ageing

Paper type Research paper

(C) Frances Lorenz, Lisa Whittaker, Julia Tazzeo and Allison Williams. Published by Emerald Publishing Limited. This article is published under the Creative Commons Attribution (CC BY 4.0) licence. Anyone may reproduce, distribute, translate and create derivative works of this article (for both commercial and non-commercial purposes), subject to full attribution to the original publication and authors. The full terms of this licence may be seen at http://creativecommons.org/licences/by/4.0/legalcode

This work was funded by a Canadian Institutes of Health Research (CIHR)/Social Science and Humanities Research Council (SSHRC) Healthy Productive Work Partnership Grant "Scaling up the Carer Inclusive Accommodating Organizations Standard" FRN: HWP - 146001 (CIHR); 890-2016-3018 (SSHRC).

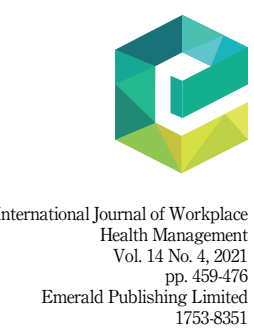

Received 31 October 2019

Revised 11 August 2020 15 February 2021

Accepted 6 March 2021 
IJWHM

14,4

\section{Introduction}

The ageing global population poses one of the 21st century's greatest challenges. By 2050, one in six people will be over the age of 65, making it the fastest-growing age group (United Nations, 2019). This demographic shift, driven by increasing global life expectancy and decreased global birth rates, poses unique economic, social and medical challenges (United Nations, 2019). In particular, the growing proportion of those over 65 will significantly impact labour force demographics, including the number of caregiver-employees. Caregiveremployees (CEs) are defined as individuals who participate in paid employment while also providing unpaid care for an adult who is dependent (i.e. a parent, spouse, sibling, and/or friend) with a serious health condition or disability (Ramesh et al., 2017).

The opportunity cost of informal eldercare is high. In Canada, CEs provide an estimated $\$ 25$ billion Canadian Dollars (CAD) per year of unpaid care (Hollander et al., 2009). Researchers used the American Time Use Survey (ATUS) to estimate that the opportunity cost of informal care in the US is $\$ 522$ billion (Chari et al., 2015), while the UK estimates an opportunity cost of $£ 119$ billion (Buckner and Yeandle, 2011). Unsurprisingly, the burden of unpaid caregiving takes a toll on CEs. The majority report difficulty juggling work and caregiving responsibilities, which negatively affects mental health, productivity, sleep quality and mood at work (Roth et al., 2015). Caregiving burden can result in increased absenteeism and presenteeism and/or CEs exiting the labour force altogether (Lorig et al., 2010). A gendered perspective is important when considering the negative effects of informal caregiving on CEs. Although global estimates vary by country, women account for anywhere from $57 \%$ to $81 \%$ of older caregivers and are more likely than ever to be simultaneously employed (Sharma et al., 2016). Internationally, the health and sustainability of CEs is a growing issue that must be addressed while considering population ageing and changing workplace demographics. The purpose of this scoping review is to summarise workplace policies and attitudes with respect to $\mathrm{CEs}$ on an international scale, highlight best practices and provide future recommendations.

\section{Literature review}

\section{Changing workplace demographics}

The modern-day definition of a typical workplace is evolving. For the first time, five different generations are participating in the labour force, from traditionalists (born before 1946) to Generation 2020; this results in greater age diversity (Meister and Willyerd, 2010). Numerous countries are now foregoing mandatory retirement ages, which provide older workers with the opportunity to remain in the workforce longer. For example, in OECD countries (the Organisation for Economic Co-operation and Development consisting of 36 member countries), employees aged 60-64 work, on average, only a few less hours per week than employees aged 50-54 (OECD, 2017). In 2016, 21\% of those aged 65-69 in OECD countries continued working; however, this statistic varies greatly by country, reaching over $40 \%$ in Iceland, Japan, Chile, Korea and New Zealand (OECD, 2017).

The workforce is also demonstrating increased gender and racial diversity. For example, in the US, female and racial minority labour force participation continues to increase (Meister and Willyerd, 2010). As the global population ages, the average age of labour force participants is expected to increase from approximately 40 in 2017 to slightly above 41 in 2030 (International Labour Office, 2018). The most drastic increases are projected to occur in Asia and Europe; however, significant increases will also occur in North America and the Arab states (International Labour Office, 2018). This demographic change will affect countries differently over the coming decades. In general, economically developed countries are projected to experience labour force decline due to a decrease in the participation of older workers and fewer available younger workers to take their place (Lisenkova et al., 2010). As a 
result, an increasingly prominent talent gap is expected to form, forcing workplaces to compete for skilled workers. Employees can expect to see increased workplace efforts to attract and retain top talent (Eversole et al., 2012).

\section{The changing nature of work}

Along with changing workplace demographics, the very nature of work is evolving due to a multitude of factors, including globalisation; increased mobile connectivity and changing values across employee generations. The millennial generation, in particular, is known for valuing work-life balance (Stewart et al., 2017). Numerous studies cite workplace flexibility as essential to attracting young talent. This includes flexible working hours, which differ from a typical 8-hour workday and telework, which allows employees to work remotely from an offsite location (Darrow, 2017; Stewart et al., 2017).

With globalisation and access to mobile technology, the future workplace is becoming increasingly digital. A significant portion of the Financial Times Global 500 companies are now based in Brazil, Russia, India, or China (Meister and Willyerd, 2010). Workplaces are moving away from large, centralised headquarters with on-site employees and are opting instead to connect employees through a digital workplace (Meister and Willyerd, 2010). As flexible working arrangements and the promotion of work-life balance become increasingly common, many workplaces have become better equipped to implement targeted services to support CEs.

\section{Caregiver-friendly workplace policies (CFWPS)}

Governments and international agencies have implemented strategies to address the issues associated with global ageing; however, workplace policy and support are fundamental to tackling the caregiving crisis. Caregiver-friendly workplace policies (CFWPs) are defined as "deliberate organisational changes - in policies, practices or target culture - to reduce workfamily conflict and/or support employees' lives outside of work." (Kelly et al., 2008, p. 310). Examples include paid or unpaid caregiver leave, flexible work arrangements, and support services (e.g. counselling, support groups and workshops). The business incentive for implementing such benefits is clear. For example, one study from the American Association for Retired Persons (AARP) suggests more generous CFWPs were associated with a $10 \%$ decrease with the intention to change jobs (AARP and ReACT, 2016a). Another study by organizational psychologist John Izzo found that the availability of family-friendly programs like CFWPs reduced employee turnover by $50 \%$ while increasing productivity by $20 \%$ (Gunderson, 2002).

This scoping review aims to identify the availability of CFWPs internationally from January 2015 to June 2019. This is the second iteration of a previous review conducted by the same research group five years ago (Ireson et al., 2018), which used the same methodology to investigate the international availability of CFWPs from 1994 to 2014. Consequently, this scoping review will identify changes in CFWP availability since the 2016 review (Ireson $\mathrm{et} \mathrm{al}$., 2018) and will discuss how current workplace and ageing demographics may have affected CFWP availability. The authors will summarize (1) the most frequently offered CFWPs; (2) contribution to CFWP availability by industry/sector and (3) innovative workplace practices. Additionally, the authors use qualitative thematic analysis of eligible articles to discuss current trends, key themes and provide future recommendations on how to best support CEs.

\section{Methods}

This scoping review followed Arksey and O’Malley (2005) methodology due to its rigour and well-established efficacy while also incorporating the recommendations proposed by Levac et al. (2010) to enhance the original framework (Peterson et al., 2017). The following
Caregiverfriendly workplace policies 
IJWHM 14,4

\section{2}

Figure 1.

Flow diagram summarising the search process used to identify eligible articles methods remain consistent with Ireson et al. (2018), allowing for a five-year comparison of findings. A flowchart summarising the search process is presented in Figure 1. Scoping reviews are a relatively new approach when compared to the traditional systematic review, which aims to synthesize available literature on a narrow research question and often includes a component of quantitative analysis. In contrast, scoping methodology addresses a broad research question and provides an overview of existing literature and relevant themes, focussing on descriptive narrative analysis. Given the diversity in the literature surrounding CFWPs, scoping study methodology provides the necessary flexibility. This review employs the following five-stage approach: (1) identifying the research question; (2) identifying relevant studies; (3) study selection; (4) charting the data and (5) collating, summarising and reporting the results (Arksey and O’Malley, 2005).

\section{Stage 1: identifying the research question}

The purpose of this scoping review is to (1) understand how workplaces are supporting the growing number of CEs through workplace culture and policy, compared to five years ago and (2) identify and prioritize actions that will improve workplace support for CEs. With this in mind, the following research question was established: "What is the current availability of CFWPs internationally, and what themes can be observed surrounding the development of such policies?". Specifically, CFWPs refers to policies or benefits offered by workplaces that directly address the provision of informal eldercare and extend beyond government policy. The literature reviewed uses diverse terminology to refer to workplace policy and employed

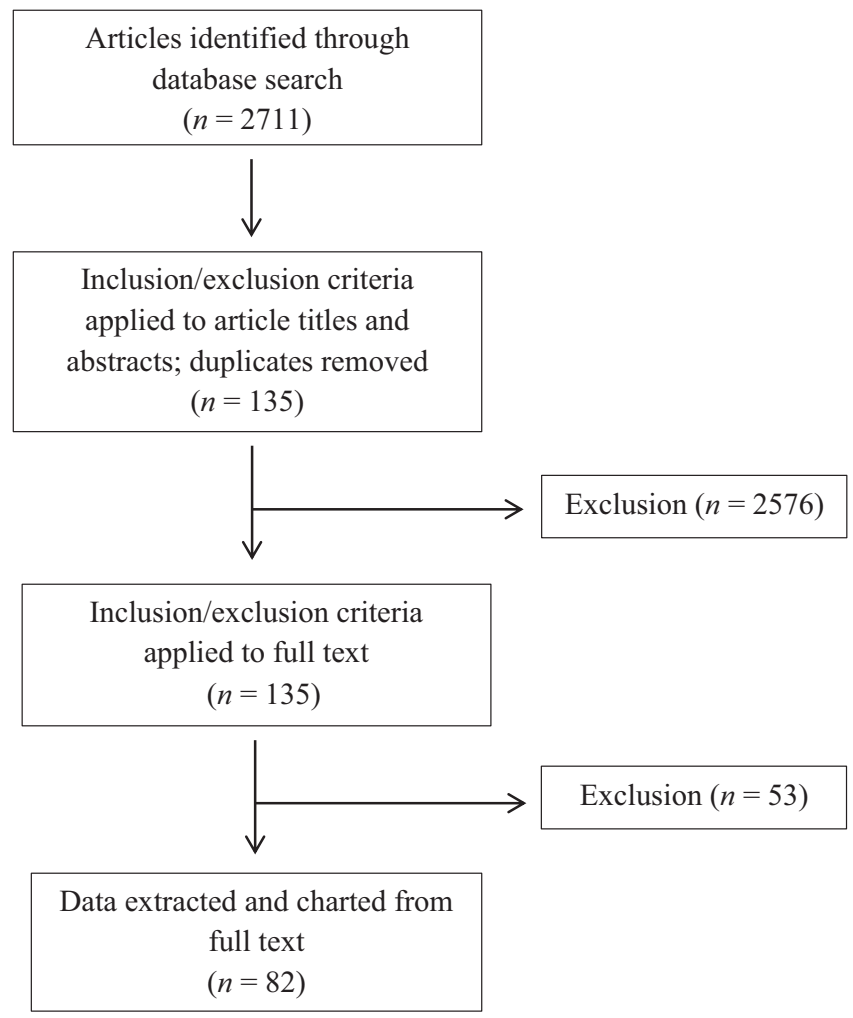


caregivers. As such, this review uses CFWP in place of all policy related terms, and CE in place of caregiver related terms.

\section{Stage 2: identifying the relevant studies}

The scoping review aims to provide a current overview of international CFWP availability over a five-year time span, from January 2015 to June 2019 inclusive. Due to a potential lack of available literature, a broad search strategy was employed in consultation with a (anonymous nstitution) librarian, including both primary literature, and literature that is peer-reviewed. The following 10 databases were selected and searched based on relevance to workplace policy: EBSCO-business source complete, Factiva, Academic OneFile, ProQuest, Web of Science, Canadian Policy Collection, LexisNexis, Eurofound, Conference Board of Canada and Scholars Portal Journals. A Boolean search was tailored to each database involving the following key words: "caregiver", "carer", "caregiving”, "adult care”, "eldercare”, "senior care", "spousal care", "workplace”, "employer", "employee”, "policies”, "policy" and "program". This method yielded 2,711 articles.

\section{Stage 3: study selection}

Studies were included based on the following criteria: (1) publication date is between January 2015 and June 2019 inclusive, (2) discusses the provision of informal/family/unpaid care to older adults, (3) discusses workplaces that have been deemed caregiver- or family-friendly related to their associated CFWP(s) and (4) workplaces are identified by name. These criteria remain consistent with Ireson et al. (2018) to ensure that potential changes in CFWP availability and perception can be observed. The inclusion of a workplace name is an essential criterion to synthesize a list of caregiver-friendly workplaces from this review. Studies were excluded if they (1) exclusively discussed policies surrounding children and childcare; (2) discussed caregivers who provide formal/paid care; (3) discussed policies available through the government or that were government-funded (however, the provision of government 'top-ups' were included) and (4) did not identify a workplace by name.

After implementing the search strategy described in stage 2 , articles were imported into the reference management software Zotero, and duplicates were removed. The inclusion/ exclusion criteria were applied to the titles and abstracts of all remaining articles, and those that could be immediately excluded were removed. This method yielded 135 articles, which were then printed, divided amongst the four authors and read in full.

\section{Stage 4: charting the data}

The inclusion/exclusion criteria were applied to the full text of 135 articles, and all four authors participated in extracting and charting the data using Microsoft Excel (2016) (Figure 2). The following information was recorded for each article: (1) author(s); (2) resource type; (3) country; (4) workplace name; (5) CFWP category (see Figure 2); (6) workplace characteristics (e.g. size, sector); (7) labour force characteristics of workplace (e.g. age and gender); (8) availability/accessibility of CFWPs; and (9) key qualitative themes and important results. The authors met to distill key thematic findings into main themes, discuss contextual variables and highlight notable CFWP offerings. The charted data were compiled, and additional hand-searches were performed to fill data gaps and create comprehensive workplace profiles.

\section{Stage 5: Collating, summarising, and reporting the results}

In stage 5, a rigorous thematic analysis was conducted, in keeping with Nowell et al. (2017), to identify patterns in workplace attitudes and policies with respect to CEs. A descriptive numerical summary of the data was also reported in the results (Arksey and O'Malley, 2005).
Caregiverfriendly workplace policies 


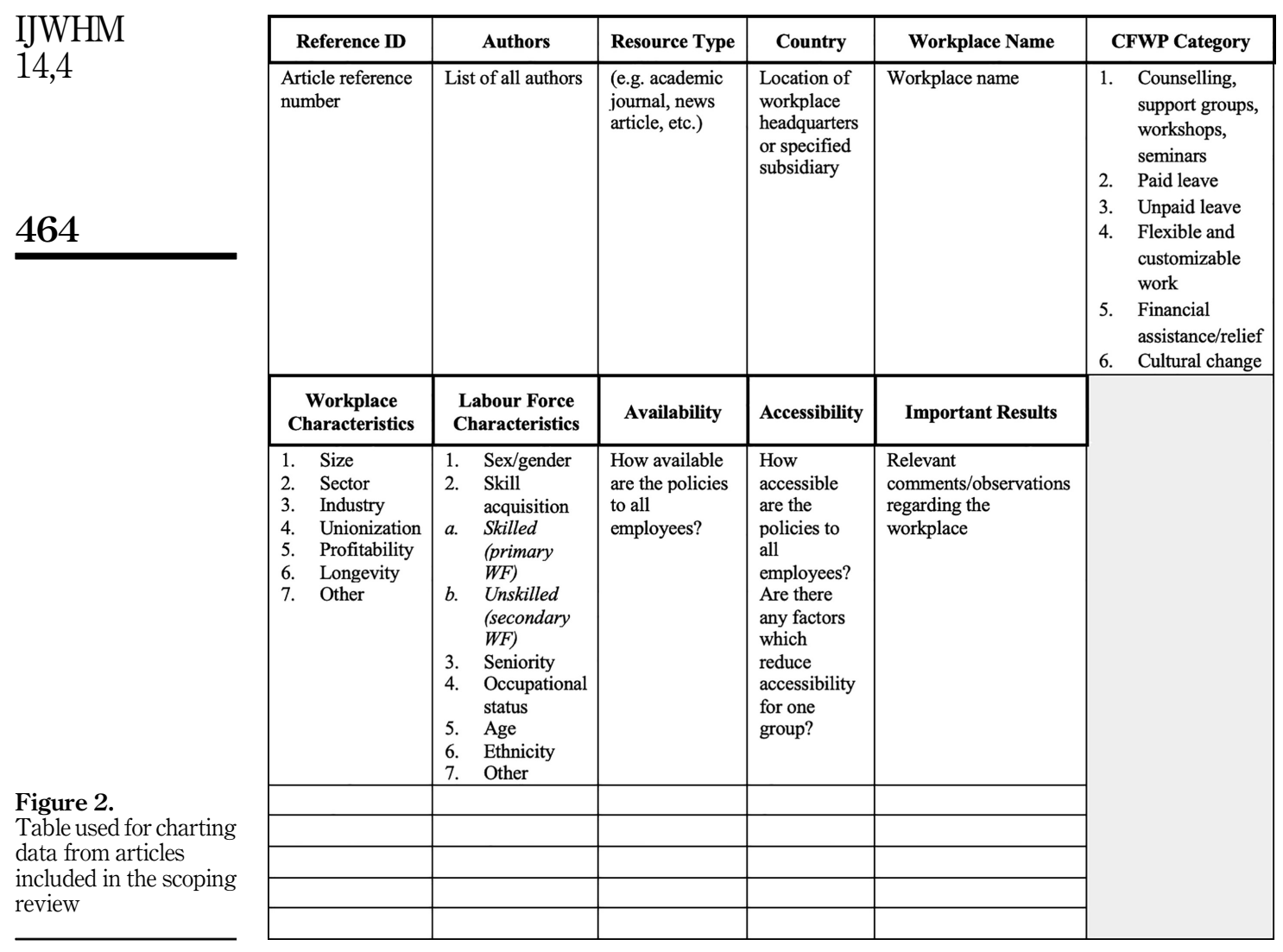

A total of 82 articles were included in the scoping study following the application of the inclusion/exclusion criteria in Stage 4. From the 82 articles, 80 unique workplaces were identified. The final sample of articles consisted of both academic literature and literature that is not peer-reviewed. Academic literature on CFWP availability and efficacy was available within the scoping study time span; however, the majority did not report a workplace name. Consequently, peer-reviewed academic articles comprised only $3.66 \%$ of the sample size, while literature that is not peer-reviewed (e.g. news articles, award recipient profiles, etc.) comprised $95.12 \%$. The scoping review also included a comprehensive case study/report conducted by the AARP and the Respect a Caregiver's Time (ReACT) coalition.

\section{Findings}

Workplace characteristics and numerical summary

Sectors which offer CFWPs. This scoping review defines workplace size by the number of employees, which is consistent with Statistics Canada and Ireson et al. (2018). Specifically, small-sized workplaces are defined as having 1-99 employees, medium-sized workplaces 100-499 employees and large-sized workplaces 500 or more employees (Leung et al., 2011). Overwhelmingly, the majority of workplaces $(88.75 \%)$ were large-sized, while $5 \%$ were medium-sized, and $6.25 \%$ were small-sized. The majority of CFWP offerings $(60 \%)$ were found in the finance, education, healthcare and technology sectors (Table 1). As found 
previously (Ireson et al., 2018), the finance sector remains a leader in CFWP availability, followed by healthcare and technology, respectively. From 1994 to 2014, Ireson et al. (2018) found education accounted for $5.7 \%$ of CFWP availability, whereas our current findings show education contributes $13.75 \%$ to CFWP availability, on par with healthcare and greater than technology.

Notably, all 11 of the higher education institutions included in the scoping review were American and demonstrated increased generosity in CFWP offerings. For example, in 2016, Emory University introduced ten fully paid days of emergency adult care per calendar year, as well as subsidized in-home adult care. In an impressive facilitation of culture change, the university organizes monthly in-person and online workshops to discuss eldercare issues, including legal advice and mental health (AARP and ReACT, 2016b). One study suggests that the observable increase in a family-friendly policy within higher education resulted from the 1993 Family Medical Leave Act (FMLA), which set a new precedent for workplace responsibility in supporting work-life balance (Schimpf and Main, 2014).

Types of CFWPs frequently offered. As found in Ireson et al. (2018), the most frequently offered CFWPs are low-cost, easily implementable services such as support groups, counselling and workshops. Notably, paid leave has become increasingly generous and widespread, with $41.25 \%$ of the included workplaces offering this policy (Table 2). For example, in 2016, the multinational accounting and consulting firm, Deloitte, instituted 16 weeks of paid time off annually for caregivers. The length and inclusivity of the policy, which can be used to care for any family member, is considered a new feat for the American finance industry. As a result, the firm has received extensive media attention and was mentioned 14 separate times in the scoping articles.

Another important finding was the emergence of backup eldercare-an entirely new category of CFWP that offers employees free or subsidized emergency care to accommodate the unpredictable nature of caregiving. Backup eldercare is now offered by $28.75 \%$ of all

\begin{tabular}{lccc}
\hline Industry/sector & $n$ & $\%$ & \\
\hline Financial & 16 & 20 & \\
Education & 11 & 13.75 & \\
Healthcare & 11 & 13.75 & \\
Technology & 10 & 12.5 & \\
Other & 10 & 11.25 & \\
Service & 9 & 8.75 & Table 1. \\
Consumer goods & 7 & 3.75 & Number of workplaces \\
Government & 3 & 2.5 & $(n)$ offering CFWPs by \\
Industrial goods & 2 & 1.25 & industry/sector \\
Legal services & 1 & &
\end{tabular}

Caregiverfriendly workplace policies

465

\begin{tabular}{lcc}
\hline Categories & $N$ & $\%^{*}$ \\
\hline Support services (i.e. workshops, counselling, etc.) & 39 & 48.75 \\
Paid leave & 33 & 41.25 \\
Backup adult care & 23 & 28.75 \\
Flexible and customisable work & 21 & 26.25 \\
Financial assistance/relief & 17 & 21.25 \\
Cultural change & 13 & 16.25 \\
Unpaid leave & 6 & 7.5
\end{tabular}

Note(s): *Percentages sum to greater than $100 \%$ as most workplaces offer multiple CFWPs

Table 2.

Frequency $(N)$ of CFWP categories offered by workplaces 
IJWHM 14,4 included workplaces, demonstrating a rapid rise in availability. Deloitte opted to join this growing trend, offering 30 days of subsidized emergency adult backup care per year.

\section{Thematic findings}

Three main themes were identified through thematic analysis: (1) inclusivity, (2) generosity and (3) culture. This section provides an in-depth qualitative analysis of each theme and their respective sub-themes.

\section{Theme 1: inclusivity}

Expanding the definition of family. The definition of family in the workplace has traditionally been referred to as a "nuclear family" structure, with gendered roles in which women perform unpaid caregiving and household duties while men engage in paid employment. Today, increased female labour force participation and changing family dynamics, including samesex couples, blended households (two or more partners residing with children from previous relationships), and wider definitions of family have rendered this definition insufficient (Bardoel et al., 1999). Additionally, cultural norms impact varying experiences of family. For example, in Asian families, it is typical for three or four generations to reside in a single household, including extended family members such as Aunts and Uncles (RothausenVange, 2005). In Indian families, Pakistani or Bangladeshi origin, it is common for employed women to reside with their parents-in-law and perform the large majority of caregiving duties (Dale, 2005).

The scoping review findings revealed that workplaces are instituting more inclusive definitions of a family than in the past (AARP and ReACT, 2016b). In particular, such flexibility was noted in paid time off. There were many instances where employees were allowed to take leave for both immediate and extended family members. In the most progressive cases, workplaces imposed no restrictions on the definition of family when offering paid caregiver leave. For example, the multinational pharmaceutical corporation Pfizer defines family to include "not just dependents, but anyone for whom the colleague is a caregiver" (AARP and ReACT, 2016b). Similarly, American insurance provider MassMutual states, "it is at the discretion of the employee to define who a 'loved one' is, and there is no requirement that the person is an immediate or extended family member" (Mayer, 2019).

Recognition of the life course. The term life-course is used to describe "the biological and experiential life paths of individuals and families as they age" (Moen and Sweet, 2004). Employees continuously experience transitions in their personal and professional roles over time, both of which impact work-life balance. As a result, considering a life-course perspective when creating workplace benefits ensures the inclusivity of employees at various life stages.

The authors found that workplaces are demonstrating greater awareness of the life course through implementing flexible policies to accommodate employees' changing needs (Attfield, 2019; Fordham, 2015; Parrella-Aureli, 2017). For example, American health service Cigna offers employees up to four weeks of paid leave per year to either bond with a child or to provide care for an ill or ageing relative (Parrella-Aureli, 2017). This trend is important in keeping up with changing workforce demographics, given that there can be as many as five different generations in one workplace (Meister and Willyerd, 2010). It should be noted that the failure to implement supportive policies across all life stages can often result in one partner reducing paid work and scaling back career goals-an outcome that disproportionately affects women (Moen and Sweet, 2004).

Anyone can be a caregiver. The authors identified gender-neutral and inclusive language in the offering of benefits, with workplaces recognizing anyone can be a caregiver. It is well documented that a lack of workplace flexibility contributes to absenteeism and decreased 
retention of both male and female employees (Taylor, 2002). A 2015 workplace survey by Emory University found that staff utilizing flexible work arrangements reported higher satisfaction $(90 \%)$ versus staff working a traditional schedule (56\%) (AARP and ReACT, 2016b). Despite this, the majority of countries with flexible work arrangements report lower utilization by male employees compared to female (Huerta et al., 2014). Simply offering flexible work arrangements is not enough; continued perceptions associating flexible policies with female employees must be deliberately addressed to improve male uptake (Atkinson and Hall, 2009). Such efforts are vital to reducing female eldercare burnout. Supporting shared responsibility - regardless of gender - can ultimately increase female labour force participation. This necessitates the adoption of gender-neutral language when offering and promoting family-friendly policies, such as the frequently observed terms "caregiver leave" or "flexible working arrangements". Increased efforts were observed to promote CFWP utilization by all employees, including deliberate efforts to increase male uptake (AARP and ReACT, 2016b).

\section{Theme 2: generosity}

The authors noted a clear increase in the generosity and extent of CFWPs offered (Table 3). Workplaces are expanding paid time off policies, increasing the number of available services and offering more progressive supports specifically addressing eldercare. Theme 2 describes innovative workplace practices identified by the authors, as well as the driving motivations behind CFWP generosity, including retention, a competitive labour market and changing employee values.

Retention versus recruitment. The need for eldercare support related to employee wellbeing and labour force participation is well documented (Clark et al., 2017; Hilbrecht et al., 2015; Skira, 2015). There is also growing research on the business incentive for offering CFWPs. In particular, reduced absenteeism increased employee retention, and improved recruitment results in a sizable return on investment (ROI) (AARP and ReACT, 2016a). A 2006 study by Thompson and Prottas estimates that for every additional family benefit offered, including those related to eldercare, employee intentions to quit decrease by $5.9 \%$. Flexibility is one of the most commonly discussed CFWPs, and there is extensive research on the business incentive for implementing flexible workplace accommodations. A report by the AARP, published in 2016, synthesized available literature on the ROI for various CFWPs. The AARP report estimates that the ROI for offering flexible work hours is between 1.70 and 4.34 (assuming an average annual salary between $\$ 50000$ and $\$ 100000$ USD), resulting from reduced absenteeism, increased retention and improved recruitment (AARP and ReACT, 2016a). A 1996 study conducted by Shepard et al. also suggests that offering flexible work accommodations can result in increased employee productivity. In their study of 50 pharmaceutical companies, they found implementing flexible work schedules increased productivity by about 10\% (Shepard et al., 1996).

Our findings show that paid leave was the second most commonly offered CFWP (Table 2). In addition to its increased availability, a common theme was observed regarding paid leave, with numerous companies launching unlimited policies that rely on managerial discretion (AARP and ReACT, 2016a; Darrow, 2017). This could be attributed to the growing literature that supports a considerable ROI for paid leave. A 2001 study by Meyer et al. estimates the availability of paid family leave results in a $12.3 \%$ increase in operating profit margin.

The media coverage that results from implementing generous CFWPs may also contribute to this observed trend. In 2004, researchers Arthur and Cook estimated that an announcement of CFWP benefits Fortune by 500 companies in the Wall Street Journal resulted in a $0.32 \%$ share price increase from 1971 to 1996 . Although a more recent study on
Caregiverfriendly workplace policies 


\section{IJWHM 14,4}

\section{8}

Allianz Life $\quad$ Finance

JP Morgan

Finance

USA

Table 3.

Innovative practices identified in the scoping review articles (including workplace name, industry and country)
Healthcare

Legal services,

Baker and McKenzie, Eli

Lilly and Company,

Facebook, EY

healthcare and

technology
Country Description of innovative practice

USA Unlimited paid time off - A growing trend in which employees have access to unlimited paid time off, alternatively referred to as 'discretionary time off'. Employees can access this benefit through collaboration with management to determine an appropriate time frame (AARP and ReACT 2016b; Darrow 2017)

USA Awareness campaign - UPMC launched a campaign entitled 'Helping Ageing Loved Ones (HALO), which aims to educate employees on eldercare and managers on how best to support CEs. This is an important effort in culture change, promoting compassion in the workplace and productive conversation between management and CEs (AARP and ReACT 2016b)

USA Eldercare support groups - Numerous workplaces are beginning to facilitate support groups in which employees can informally discuss carer responsibilities and challenges, as well as CFWPs. Support groups are led by employee volunteers, with meeting spaces and support provided by the workplace (AARP and ReACT 2016b; Fordham 2015; Mayer 2018; Eisenberg 2017)

USA Educational workshops - Allianz Life provides quarterly educational sessions for CEs. Topics of discussion address employee inquiries, such as financial and legal paperwork, finding home care, dementia signs, etc. (AARP and ReACT 2016b)

Healthcare Coverage - Employees can add their partner, both parents and parents-inlaw to a benefits plan, which covers homecare assistance, dental and health screening. Parents of any age can be added (Calnan, 2015)

Fannie Mae $\quad$ Finance USA On-site care consultant - A dedicated eldercare consultant is available to employees all year round to provide guidance and support. But, access is unlimited (AARP and ReACT 2016b)

this phenomenon has not been conducted, it remains a compelling incentive for CFWP implementation.

Competitive workforcelattracting talent. An acute global talent shortage is predicted to occur by 2020, presenting a clear discrepancy between the skills of available job applicants and the skills in demand (Meister and Willyerd, 2010). Thus, it is no surprise the authors identified a strong desire to attract top talent in today's competitive labour market (Fordham, 2015; Burjek, 2019; Mayer, 2019; Campus and Community News Staff, 2018). The bid to attract talent means 
workplaces must accommodate the various needs of an increasingly diverse labour force, with generational, gender and cultural differences. The combination of an ageing population with increased care needs and a greater desire for work-life balance continues to shape expectations of workplace benefits. To be regarded as a top employer, simply offering CFWPs is no longer enough; policies must be diverse, extensive and generous. The race to improve CFWP offerings was particularly apparent in the technology sector, which is understandable considering it will face one of the most acute talent shortages. According to a 2018 study by Zaharee $e t$ al., flexible work hours and work-life balance policies serve to enhance the attraction and retention of technically skilled workers across all generations.

Changing values of employees. By 2025, it is estimated that millennials will comprise $75 \%$ of the global workforce (Winograd and Hais, 2014). As a result, changes in the corporate culture and CFWP offerings will continue to be driven by millennial values. In particular, the observed increase in benefit extent and generosity may be influenced by the millennial emphasis on work-life balance, with numerous workforces citing generous work-life benefits as essential for attracting young talent (AARP and ReACT, 2016a; Darrow, 2017; Stewart et al., 2017). Currently, it is estimated that millennials account for one-quarter of CEs in the US, and as the population continues to age, this number will likely increase. This further emphasises the need for CFWPs (Flinn, 2018).

\section{Theme 3: culture}

This scoping review has determined the enhanced availability of CFWPs (Table 2); however, if such policies are not supported by the workplace culture, employees may be discouraged from using them, resulting in minimal positive impact. Halpern (2005) suggests workplaces must view work-life policies as integral to their business practice rather than as an accommodation for specific individuals. The authors identified targeted efforts to incite culture change and frame the use of CFWPs as an important business practice. Notable culture change initiatives include fostering compassion in the workplace; encouraging practices of work-life balance and increasing awareness of available benefits.

Supporting work-life balance. There were numerous workplaces identified in the scoping review that aimed to create a workplace culture that supports work-life balance and encourages the use of CFWPs (Groom, 2015; Mayer, 2017; Sipek, 2015). For example, A British energy provider Centrica trains managers on the unique circumstances of CEs to foster supervisor compassion and collaboration. This practice is important because an employee's perception of workplace support is highly dependent on their immediate supervisor (Gurvis and Patterson, 2005). Another example is the American technology company Akamai. This workplace offers a comprehensive wellness program that includes practical services such as financial counselling and health promotion programs, such as onsite meditation and yoga (Mayer, 2017). Akamai promotes such benefits through monthly "benefits blasts".

Fostering compassion. An important aspect of culture change in the workplace is the fostering of empathy towards every employee's life circumstance. The authors noticed a trend specific to workplaces implementing strategies to achieve this (AARP and ReACT, 2016b; Burjek, 2019). A US mortgage loan company, Fannie Mae, is a particularly outstanding case with its implementation of the "Ageing Workforce Initiative". The workplace's eldercare team organized a "day-in-the-life" workshop which described typical scenarios CEs experience, followed by workplace solutions to support these employees (AARP and ReACT, 2016b).

Increasing benefit awareness. The scoping review identified workplace efforts to bring awareness of CFWPs through internal communications and social networks (AARP and ReACT, 2016b; Fordham, 2015; Sipek, 2015). For example, a multinational law firm, Baker and McKenzie, publishes blogs written by employees who discuss their experiences utilizing
Caregiverfriendly workplace policies 
IJWHM 14,4

various benefits (Fordham, 2015). Other workplaces, such as Emory University located in the US, use targeted messaging to more effectively provide information when communicating with a vast number of departments and employees. For example, they may send an email about caregiving to groups that are more likely to be CEs, such as the 55-65 age group (AARP and ReACT, 2016b).

\section{Discussion}

This scoping review successfully summarised and described the current landscape of CFWP offerings, identifying an increase in CFWP availability, inclusivity and generosity alongside improved workplace attitudes towards CEs. Certain sectors are notably leading in CFWP offerings, namely the financial, education, healthcare and technology sectors. Other sectors lag behind, such as consumer goods, industrial goods, government and legal services. Improvements to CFWP availability have been made; however, more work needs to be met to keep up with changing employee values, the ageing population, and a widening talent gap.

\section{Differences over five years}

The scoping review revealed notable changes in CFWP availability from January 2015 to June 2019 in comparison to 1994-2014 (Ireson et al., 2018). Following the same inclusionexclusion criteria, this review identified 80 caregiver-friendly workplaces from the literature over a five-year period, compared to the previous 88 workplaces identified over a 20-year period. Finance, healthcare, and technology remained in the top four industries for CFWP availability, and education moved from the fifth largest contributor of CFWP availability $(5.7 \%)$ to the second largest (13.75\%) (Figure 3).

Regarding the types of CFWPs offered, support services remained the most common. However, paid leave has become increasingly available, moving from the fifth to the second most common type of CFWP offered (Figure 4). As previously discussed, 'adult care' is an entirely new CFWP, which contributed more to total CFWP availability than did flexible work; financial assistance and unpaid leave individually (Figure 4). It is unclear why flexible work, financial assistance and unpaid leave were found to be less available in the 2015-2019 period when compared to the 1994-2014 period (Ireson et al., 2018). One possibility is that these traditional CFWPs are now well-established and expected rather than being recognized and reported on as progressive policies. Thus, as workplaces aim to gain a competitive

Figure 3.

A comparison of the number of workplaces (n) offering CFWPs, by industry/sector from 2004 to 2014 (Ireson et al.,2018), versus 2015 to June 2019

\begin{tabular}{|c|c|c|c|c|c|}
\hline \multicolumn{3}{|l|}{2004 - 2014} & \multicolumn{3}{|l|}{2015 - 2019} \\
\hline Industry/sector & $\mathrm{n}$ & $\%$ & Industry/sector & $n$ & $\%$ \\
\hline Financial & 26 & $29.5-$ & $\longrightarrow$ Financial & 16 & 20 \\
\hline Healthcare & 12 & 13.6 & Education & 11 & 13.75 \\
\hline Technology & 11 & 12.5 & Healthcare & 11 & 13.75 \\
\hline Consumer goods & 9 & 10.2 & Technology & 10 & 12.5 \\
\hline Education & 5 & 5.7 & Other & 10 & 12.5 \\
\hline Other & 4 & 4.5 & Service & 9 & 11.25 \\
\hline Government & 4 & 4.5 & Consumer goods & 7 & 8.75 \\
\hline Transportation & 4 & 4.5 & Government & 3 & 3.75 \\
\hline Utilities & 4 & 4.5 & Industrial goods & 2 & 2.5 \\
\hline Basic materials & 3 & 3.4 & Legal services & 1 & 1.25 \\
\hline Legal services & 3 & 3.4 & & & \\
\hline Industrial goods & 2 & 2.3 & & & \\
\hline Service & 1 & 1.1 & & & \\
\hline
\end{tabular}


advantage through their benefit offerings, we are seeing more generous and diverse policies such as paid time off.

\section{Strengths and limitations of the review}

This scoping review comprehensively synthesized CFWP availability to better understand how workplaces are supporting CEs. In order to encourage further improvements to CFWP offerings, this review summarized the characteristics of caregiver friendly workplaces and highlighted best practices. To understand current trends and attitudes in CFWP offerings, this review identifies key themes and provides actionable recommendations for workplaces and government.

The scoping review methodology has a few limitations. The vast majority of included articles $(95.12 \%)$ were not peer-reviewed. As a result, articles often highlighted noteworthy CFWPs rather than providing a comprehensive overview of workplace offerings, causing potential information gaps. Some articles may have highlighted a subsidiary location rather than the workplace's headquarters or vice versa. This is a limitation as, within a single workplace, CFWPs will vary across geography. Only English-speaking articles were included in the scoping review, which limited the number of countries and subsequent workplaces identified. In the future, it would be beneficial to perform a broader search in multiple languages to better capture an international perspective. Finally, of the 80 workplaces identified, $75 \%$ were from the US, $17.5 \%$ from the UK and $7.5 \%$ from Canada. The dominance of these three geographic locations, and the US in particular, limited the scoping review's international perspective.

The scoping review and resulting thematic analysis allowed the authors to develop recommendations for workplaces and government to improve workplace support for CEs (Table 4). The recommendations remain the same as in Ireson et al. (2018); however, the order

\begin{tabular}{|c|c|c|c|c|c|}
\hline $2004-2014$ & & & $2015-2019$ & & \\
\hline Categories & $\mathbf{N}$ & $\% *$ & Categories & $\mathbf{N}$ & $\% *$ \\
\hline $\begin{array}{l}\text { Support Services (i.e. } \\
\text { workshops, counselling, etc.) }\end{array}$ & 61 & 69.3 & $\begin{array}{l}\text { Support Services (i.e. } \\
\text { workshops, counselling, etc.) }\end{array}$ & 39 & 48.75 \\
\hline $\begin{array}{l}\text { Flexible and customizable } \\
\text { work }\end{array}$ & 43 & 48.9 & Paid leave & 33 & 41.25 \\
\hline Financial assistance/relief & 35 & 398 & diult & 23 & 28.75 \\
\hline Unpaid leave & 27 & 30.7 & nd customizab & 21 & 26.25 \\
\hline Paid leave & 24 & 27.3 & Financial assistance/relief & 17 & 21.25 \\
\hline Cultural change & 21 & 23.9 & Cultural change & 13 & 16.25 \\
\hline & & & Unpaid leave & 6 & 7.5 \\
\hline
\end{tabular}

1 Facilitate collaboration between policymakers and workplaces to support caregivers in balancing work and unpaid caregiving

2 Provide training to managers to recognize and support CEs

3 Advocate for campaigns that address stigma related to caregiving

4 Create awareness of existing human resources policies and CFWPs

5 Identify CEs in the workplace and recognise their unique needs

6 Create CFWPs that accommodate diverse CEs (as defined by age, sex, class, gender, immigration status, family structure, caregiving responsibilities, etc.)

7 Work to change workplace culture to better accept and accommodate CEs

8 Provide flexibility in work schedules, and if possible, provide CEs some choice in strategies to best manage work and caregiving responsibilities

Note(s): CFWPs, caregiver-friendly workplace policies; CEs, caregiver-employees
Caregiverfriendly workplace policies

Figure 4. A comparison of the frequency $(\mathrm{N})$ of $\mathrm{CFWP}$ categories offered by workplaces from 2004

to 2014 (Ireson et al.,

2018) versus January 2015-June 2019
Table 4. Recommendations for workplaces and government to improve workplace support for $\mathrm{CEs}$ in a priority order 
IJWHM 14,4

of priority has changed. This is a result of notable progress in recognizing the unique needs of CEs, creating inclusive accommodations and increasing CFWP availability and flexible work options (Figure 5). The re-prioritization is a step forward; however, more work needs to be done to address these recommendations and make caregiver friendly workplaces commonplace.

\section{2}

\section{Conclusion}

This paper followed Arksey and O'Malley (2005) scoping review methodology to determine the international availability of CFWPs from January 2015 to June 2019 inclusive. The results were compared to an earlier scoping review conducted by the same research group five years ago (Ireson et al., 2018), which used the same methodology to investigate the international availability of CFWPs from 1994 to 2014. The scoping review findings revealed that the four leading industries currently providing CFWPs are finance, education, healthcare and technology. Support services remain the most commonly offered CFWP, accounting for $48.75 \%$ of total CFWPs available. This is followed closely by paid leave, adult care and flexible work arrangements.

CFWPs have become more inclusive, which is evident through the use of expanded definitions of a family; the use of gender-neutral language and recognition of the complete life course. Additionally, CFWPs have become increasingly generous. Finally, a clear culture shift has taken place, noted in efforts to support work-life balance; foster supervisor compassion and improve CFWP awareness. Overall, clear progress has been made since the first scoping review conducted by Ireson et al. (2018). Future recommendations have been made to encourage further support for CEs in the workplace, an issue that continues to grow as the average age of the global population increases (United Nations, 2016).

Based on the above limitations, there are numerous future steps that can be taken to strengthen the scoping review. Firstly, analysing the literature in multiple languages would allow for a more encompassing international perspective. Additionally, rigorous methodological approaches are needed to better understand the workplace benefits of offering CFWPs both individually and in combination. This is particularly true for newer CFWPs such as backup eldercare. Finally, more research should be conducted to understand how CFWPs can be optimized for all employees including racial and minority groups.

Figure 5.

A comparison of the priority of recommendations for workplaces and government from 2004 to 2014 (Ireson et al., 2018) versus January 2015-June 2019

\begin{tabular}{l}
2004 - 2014 \\
\hline 1 Identify CEs in the workplace and recognise their unique needs \\
\hline 2 Work to change workplace culture to better accept and accommodate CEs \\
\hline 3 Create CFWPs that accommodate diverse CEs (as defined by age, sex, class, gender, \\
immigration status, family structure, care--giving responsibilities, etc.) \\
\hline 4 Create awareness of existing Human Resources policies and CFWPs \\
\hline 5 Provide training to managers to recognize and support CEs \\
\hline 6 Provide flexibility in work schedules, and, if possible, provide CEs some choice in choosing \\
strategies to best manage work and care-giving responsibilities \\
\hline 7 Facilitate collaboration between policy makers and employers to support caregivers in \\
balancing work and unpaid caregiving
\end{tabular}




\section{References}

AARP, and ReACT (2016a), "Determining the return on investment: supportive policies for employee caregivers", available at: https://respectcaregivers.org/wp-content/uploads/2016/04/AARP-ROIReport-FINAL-4.1.16.pdf.

AARP, and ReACT (2016b), "Supporting working caregivers: case studies of promising practices", available at: https://respectcaregivers.org/wp-content/uploads/2017/05/AARP-ReAct-MASTER-web.pdf.

Arksey, H. and O'Malley, L. (2005), "Scoping studies: towards a methodological framework", International Journal of Social Research Methodology, Vol. 1, pp. 19-32.

Arthur, M.M. and Cook, A. (2004), "Taking stock of work-family initiatives: how announcements of "family-friendly" human resource decisions affect shareholder value", Industrial and Labor Relations Review, Vol. 57 No. 4, pp. 599-613, doi: 10.2307/4126685.

Atkinson, C. and Hall, L. (2009), "The role of gender in varying forms of flexible working", Gender, Work and Organization, doi: 10.1111/j.1468-0432.2009.00456.x.

Attfield, P. (2019), "The No. 1 thing employers can do for workers who are balancing eldercare with careers", The Globe and Mail, available at: https://www.theglobeandmail.com/business/careers/ article-the-no-1-thing-that-employees-especially-women-need-to-balance-work/.

Bardoel, E.A., Moss, S.A., Smyrnios, K. and Tharenou, P. (1999), "Employee characteristics associated with the provision of work-family policies and programs", International Journal of Manpower. doi: 10.1108/01437729910302741.

Buckner, L. and Yeandle, S. (2011), Valuing Carers 2011 Calculating the Value of Carers' Support, University of Leeds, UK, available at: https:/www.carersuk.org/about-us/36-for-professionals/ policy-eng/report/5021-valuing-carers-2011-calculating-the-value-of-carers-support.

Burjek, A. (2019), "Caregiving perks enter the 21st century", available at: https://www.workforce.com/ 2019/03/07/caregiving-perks-enter-21st-century/ (accessed 26 July 2019).

Calnan, M. (2015), "What can employers do to meet the demand for eldercare?", available at: https:// www.employeebenefits.co.uk/issues/march-2015/what-can-employers-do-to-meet-the-demandfor-eldercare/ (accessed 30 July 2019).

Campus and Community News Staff (2018), "Support for families: syracuse university announces new resources and increased subsidies for child care and elder care", available at: https://news.syr. edu/blog/2018/07/26/support-for-families-syracuse-university-announces-new-resources-andincreased-subsidies-for-child-care-and-elder-care/ (accessed 26 July 2019).

Chari, A., Engberg, J., Ray, K. and Mehrotra, A. (2015), "The opportunity costs of informal elder-care in the United States: new estimates from the American time use survey", Health Services Research, Vol. 50 No. 3, pp. 871-882, doi: 10.1111/1475-6773.12238.

Clark, M., Rudolph, C. and Zhdanova, L. (2017), "Organizational support factors and work-family outcomes: exploring gender differences”, Journal of Family Issues, Vol. 38 No. 11, doi: 10.1177/ $0192513 X 15585809$.

Dale, A. (2005), "Combining family and employment: evidence from Pakistani and Bangladeshi women", in Houston, D.M. (Ed.), Work-Life Balance in the 21st Century, pp. 230-245, doi: 10. 1057/9780230373594_12.

Darrow, B. (2017), "Microsoft employees now get 4 Weeks of paid family care leave", available at: https://fortune.com/2017/06/27/microsoft-paid-family-care-leave/ (accessed 25 July 2019).

Eisenberg, A. (2017), "Why employers need to offer benefits to informal caregivers", available at: https://www.benefitnews.com/news/why-employers-need-to-offer-benefits-to-informalcaregivers (accessed 30 July 2019).

Eversole, B., Venneberg, D. and Crowder, C. (2012), "Creating a flexible organizational culture to attract and retain talented workers across generations", Advances in Developing Human Resources, Vol. 14 No. 4, pp. 607-625, doi: 10.1177/1523422312455612.

Caregiverfriendly workplace policies 
IJWHM 14,4

Flinn, B. (2018), "Millennials: the emerging generation of family caregivers", p. 11, available at: https:// www.aarp.org/content/dam/aarp/ppi/2018/05/millennial-family-caregivers.pdf.

Fordham, L. (2015), "Baker and McKenzie sees benefits of supporting working carers", available at: https://www.employeebenefits.co.uk/issues/september-online-2015/baker-and-mckenzie-seesbenefits-of-supporting-working-carers/ (accessed 22 July 2019).

Groom, B. (2015), "UK employers turn to caring for the carers", available at: https://www.ft.com/ content/b2eb7ce4-2175-11e5-ab0f-6bb9974f25d0 (accessed 30 July 2019).

Gunderson, M. (2002), Rethinking Productivity from a Workplace Perspective, Canadian Policy Research Networks, Ottawa, ON, p. 21.

Gurvis, J. and Patterson, G. (2005), "Balancing act: finding equilibrium between work and life", Leadership in Action, Vol. 24 No. 6, pp. 4-9, doi: 10.1002/lia.1091.

Halpern, D.F. (2005), "How time-flexible work policies can reduce stress, improve health, and save money", Stress and Health, Vol. 21 No. 3, pp. 157-168, doi: 10.1002/smi.1049.

Hilbrecht, M., Lero, D., Schryer, E., Mock, S. and Smale, B. (2015), "Understanding the association between time spent caregiving and well-being among employed adults: testing a model of work-life fit and sense of community", Vol. 20 No. 2, pp. 162-180, doi: 10.1080/13668803.2015. 1112254 .

Hollander, M., Liu, G. and Chappell, N. (2009), "Who cares and how much? The imputed economic contribution to the Canadian healthcare system of middle-aged and older unpaid caregivers providing care to the elderly", Healthcare Quarterly, Vol. 12 No. 2, pp. 42-29, doi: 10.12927/hcq. 2009.20660.

Huerta, M.C., Adema, W., Baxter, J., Han, W.J., Lausten, M., Lee, R. and Waldfogel, J. (2014), “Fathers' leave and fathers' involvement: evidence from four OECD countries", European Journal of Social Security, Vol. 16 No. 4, pp. 308-346, doi: 10.1177/138826271401600403.

International Labour Office (2018), "World employment social outlook", p. 79, available at: https:// www.ilo.org/wcmsp5/groups/public/—dgreports/_dcomm/- publ/documents/publication/ wcms_615594.pdf.

Ireson, R., Sethi, B. and Williams, A. (2018), "Availability of caregiver-friendly workplace policies (CFWPs): an international scoping review", Health and Social Care in the Community, Vol. 26 №. 1, pp. e1-e14, doi: $10.1111 /$ hsc.12347.

Kelly, E.L., Ernst-Kossek, E., Hammer, L.B., Durham, M., Bray, J., Chermack, K., Murphy, L.A. and Kaskubar, D. (2008), "Getting there from here: research on the effects of workfamily initiatives on work-family conflict and business outcomes", Academy of Management Annals, Vol. 2 No. 1, pp. 305-349.

Leung, D., Rispoli, L. and Gibson, B. (2011), Small, Medium-Sized and Large Businesses in the Canadian Economy: Measuring Their Contribution to Gross Domestic Product in 2005, Statistics Canada, Ottawa, available at: http://www.statcan.gc.ca/pub/11f0027m/ 11f0027m2011069-eng.pdf.

Levac, D., Colquhoun, H. and O'Brien, K.K. (2010), "Scoping studies: advancing the methodology", Implementation Science, Vol. 5 No. 1, p. 69, doi: 10.1186/1748-5908-5-69.

Lisenkova, K., McQuaid, R. and Wright, R. (2010), "Demographic change and labour markets: twentyfirst century society”, Economics of an Ageing World, Vol. 5, pp. 243-259, doi: 10.1080/17450144. 2010.480828 .

Lorig, K., Thompson-Gallagher, D. and Traylor, L. (2010), "Building better caregivers: a pilot online support workshop for family caregivers of cognitively impaired adults", Journal of Applied Gerontology, doi: 10.1177/0733464810389806.

Mayer, K. (2017), "Benefits professional of the year creates a balance for akamai employees", available at: https://www.benefitnews.com/news/benefits-professional-of-the-year-creates-a-balance-forakamai-employees (accessed 30 July 2019). 
Mayer, K. (2018), "Facebook raised the bar on employee benefits. Now it's hoping to start a workplace revolution", available at: https://www.benefitnews.com/news/facebook-boosts-employeebenefits-hopes-to-start-revolution (accessed 30 July 2019).

Mayer, K. (2019), "In bid for top talent, MassMutual the latest employer to bulk up benefits", available at: https://www.benefitnews.com/news/massmutual-the-latest-employer-to-bulk-up-benefits (accessed 19 July 2019).

Meister, J. and Willyerd, K. (2010), The 2020 Workplace, HarperCollins.

Meyer, C.S., Mukherjee, S. and Sestero, A. (2001), "Work-family benefits: which ones maximize profits?”, Journal of Managerial Issues, Vol. 13 No. 1, pp. 28-44, Retrieved from JSTOR.

Moen, P. and Sweet, S. (2004), "From 'work-family' to 'flexible careers", Community, Work and Family, Vol. 7 No. 2, pp. 209-226, doi: 10.1080/1366880042000245489.

Nowell, L.S., Norris, J.M., White, D.E. and Moules, N.J. (2017), "Thematic analysis: striving to meet the trustworthiness criteria”, International Journal of Qualitative Methods. doi: 10.1177/ 1609406917733847.

OECD (2017), Pensions at a Glance 2017: OECD and G20 Indicators, OECD Publishing, Paris. doi: 10. 1787/pension_glance-2017-en.

Parrella-Aureli, A. (2017), "Organizations caring more about caregiving benefits", available at: https:// www.workforce.com/2017/09/18/organizations-caring-caregiving-benefits/ (accessed 22 July 2019).

Peterson, J., Pearce, P., Ferguson, L.A. and Langford, C.A. (2017), "Understanding scoping reviews: definition, purpose, and process", Vol. 29 No. 1, pp. 12-16, doi: 10.1002/2327-6924.12380.

Ramesh, S., Ireson, R. and Williams, A. (2017), Title Omitted for Blind Review, Published manuscript.

Roth, D., Fredman, L. and Haley, W. (2015), "Informal caregiving and its impact on health: a reappraisal from population-based studies", The Gerontologist, Vol. 55 No. 2, pp. 309-319, doi: 10.1093/geront/gnu177.

Rothausen-Vange, T.J. (2005), "Family diversity: a sloan work and family encyclopedia entry", Sloan Network Encyclopedia, available at: https://wfrn.org/wp-content/uploads/2018/09/FamilyFriendly_Community-encyclopedia-1.pdf.

Schimpf, C.T. and Main, J.B. (2014), "The distribution of family-friendly benefits policies across higher education institutions: a cluster Analysis", Paper Presented at 2014 ASEE Annual Conference and Exposition, Indianapolis, Indiana, available at: https://peer.asee.org/23133.

Sharma, N., Chakrabarti, S. and Grover, S. (2016), "Gender differences in caregiving among familyCaregivers of people with mental illnesses". Vol. 6 No. 1, doi: 10.5498/wjp.v6.i1.7.

Shepard, E., Clifton, T.J. and Kruse, D. (1996), "Flexible work hours and productivity: some evidence from the pharmaceutical industry", Industrial Relations: A Journal of Economy and Society, Vol. 35 No. 1, pp. 123-139, doi: 10.1111/j.1468-232X.1996.tb00398.x.

Sipek, S. (2015), "Caring for the caregiver", available at: https://www.workforce.com/2015/12/31/ caring-for-the-caregiver/ (accessed 30 July 2019).

Skira, M. (2015), "Dynamic wage and employment effects of elder parent care", International Economic Review, Vol. 65 No. 1, pp. 63-93, doi: 10.1111/iere.12095.

Stewart, J.S., Oliver, E.G., Cravens, K.S. and Oishi, S. (2017), "Managing millennials: embracing generational differences", Business Horizons, Vol. 60 No. 1, pp. 45-54, doi: 10.1016/j.bushor.2016. 08.011 .

Taylor, S. (2002), The Employee Retention Handbook, Chartered Institute of Personnel and Development, London.

Thompson, C.A. and Prottas, D.J. (2006), "Relationships among organizational family support, job autonomy, perceived control, and employee well-being", Journal of Occupational Health Psychology, Vol. 11 No. 1, pp. 100-118, doi: 10.1037/1076-8998.10.4.100.

Caregiverfriendly workplace policies

(1) 
IJWHM

14,4

476
United Nations (2016), “Ageing”, available at: https://www.un.org/en/sections/issues-depth/ageing/ (accessed 6 August 2019).

United Nations (2019), “World population prospects 2019: highlights”, available at: https://population. un.org/wpp/Publications/Files/WPP2019_10KeyFindings.pdf.

Winograd, M. and Hais, M. (2014), "How millenials could upend Wall Street and corporate America", p. 19, available at: https://www.brookings.edu/wp-content/uploads/2016/06/Brookings_ Winogradfinal.pdf.

Zaharee, M., Lipkie, T., Mehlman, S.K. and Neylon, S.K. (2018), "Recruitment and retention of earlycareer technical talent”, Research-Technology Management, Vol. 61 No. 5, pp. 51-61, doi: 10.1080/ 08956308.2018.1495966.

\section{Corresponding author}

Allison Williams can be contacted at: awill@mcmaster.ca

For instructions on how to order reprints of this article, please visit our website: 